\title{
Second meal effect: modified sham feeding does not provoke the release of stored triacylglycerol from a previous high-fat meal
}

\author{
Kim G. Jackson ${ }^{1}$, M. Denise Robertson ${ }^{2}$, Barbara A. Fielding ${ }^{2}$, Keith N. Frayn ${ }^{2}$ \\ and Christine M. Williams ${ }^{1}$ \\ ${ }^{1}$ Hugh Sinclair Unit of Human Nutrition, School of Food Biosciences, University of Reading, Reading RG6 6AP, UK \\ ${ }^{2}$ Oxford Lipid Metabolism Group, Nuffield Department of Clinical Medicine, University of Oxford, Oxford OX2 6HE, UK
}

(Received 28 February 2000 - Revised 2 August 2000 - Accepted 23 August 2000)

\begin{abstract}
The present study was carried out to determine whether cephalic stimulation, associated with eating a meal, was sufficient stimulus to provoke the release of stored triacylglycerol (TAG) from a previous high-fat meal. Ten subjects were studied on three separate occasions. Following a $12 \mathrm{~h}$ overnight fast, subjects were given a standard mixed test meal which contained $56 \mathrm{~g}$ fat. Blood samples were taken before the meal and for $5 \mathrm{~h}$ after the meal when the subjects were randomly allocated to receive either water (control) or were modified sham fed a low-fat $(6 \mathrm{~g}$ fat) or moderate-fat (38 g fat) meal. Blood samples were collected for a further $3 \mathrm{~h}$. Compared with the control, modified sham feeding a low- or moderate-fat meal did not provoke an early entry of TAG, analysed in either plasma or TAG-rich lipoprotein (TRL) fraction (density $<1.006 \mathrm{~kg} / \mathrm{l})$. The TRL-retinyl ester data showed similar findings. A cephalic phase secretion of pancreatic polypeptide, without a significant increase in cholecystokinin levels, was observed on modified sham feeding. Although these data indicate that modified sham feeding was carried out successfully, analysis of the fat content of the expectorant showed that our subjects may have accidentally ingested a small amount of fat $(0.7 \mathrm{~g}$ for the low-fat meal and $2.4 \mathrm{~g}$ for the moderate-fat meal). Nevertheless, an early TAG peak following modified sham feeding was not demonstrated in the present study, suggesting that significant ingestion of food, and not just orosensory stimulation, is necessary to provoke the release of any TAG stored from a previous meal.
\end{abstract}

Triacylglycerol: Modified sham feeding: Sequential meal ingestion

Many studies of the postprandial responses to fat ingestion have been conducted using a single test meal, with a peak in triacylglycerol (TAG) concentration usually occurring 3-4 $\mathrm{h}$ after eating the meal. We have previously shown that different events occur on sequential meal ingestion when a second meal is eaten within a few hours of a previous meal. Notably, there is a rapid appearance of chylomicrons into the circulation, with a peak at approximately $1 \mathrm{~h}$ after the second meal (Peel et al. 1993; Fielding et al. 1996; Evans et al. 1998). Fielding et al. (1996) have demonstrated that chylomicrons released into the circulation following the second meal carried fatty acids which were very similar to those consumed in the first meal. Following on from these observations, Evans et al. (1998) showed that this effect occurred whether the second meal contained fat or was fatfree. It appears, therefore, that a proportion of dietary fat from the first meal is stored in a location from which it is rapidly released on eating the second meal. The location of the storage pool and the stimuli able to cause its release are presently unknown.

Findings from a recent study have shown that oro-nasal (cephalic) stimulation, generated from modified sham feeding full-fat cream cheese on crackers, was able to exaggerate the postprandial plasma TAG response to a standard $50 \mathrm{~g}$ fat load given as capsules (Mattes, 1996). Since this exaggerated response was only observed when the full-fat cream cheese and not low-fat cheese or dry crackers were modified sham fed, the author hypothesised that receptors in the oro-nasal region may be able to detect some aspect of the chemical composition of dietary fat and so modify the postprandial lipaemic response. Similar findings were observed over 40 years ago by Mendeloff (1954) who showed that modified sham feeding an attractive meal was able to improve the entry into the

\footnotetext{
Abbreviations: CCK, cholecystokinin; IAUC, incremental area under the curve; LFS, low-fat modified sham fed meal; MFS, moderate-fat modified sham fed meal; PP, pancreatic polypeptide; RE, retinyl ester; TAG, triacylglycerol; TRL, TAG-rich lipoprotein.

* Corresponding author: Dr Kim G Jackson, fax + 440118 9310080, email k.jackson@afnovell.reading.ac.uk
} 
circulation of vitamin A given as retinyl palmitate $2 \mathrm{~h}$ earlier. Mendeloff (1954) postulated that cephalic stimulation was somehow able to activate the lacteals to expel their contained vitamin A into the bloodstream. The possibility that cephalic stimulation might modify the lipaemic response to a previously eaten meal is important in view of increasing evidence that elevated levels of TAG during the postprandial state play a considerable role in the pathogenesis of CHD (Zilversmit, 1995; Patsch et al. 1992). Thus, the aim of the present study was to examine whether oro nasal stimulation was one of the stimuli responsible for the release of stored TAG from a previous meal. This stimulation was performed by modified sham feeding (chewing and expectorating) low- and moderate-fat meals $5 \mathrm{~h}$ after consuming a standard fat load. The vitamin A loading method was used to label chylomicrons and their remnants with retinyl ester (RE) and provide a clearer picture of chylomicron-specific postprandial responses. Measurements of pancreatic polypeptide (PP), a cephalic phase-stimulated hormone (Mattes, 1997) and cholecystokinin (CCK), a hormone released by food ingestion (Glasbrenner et al. 1994) were included as markers of successful modified sham feeding. The opportunity was also taken to develop and validate a method for modified sham feeding that may be useful in future studies.

Results from the present study have been published previously in abstract form (Jackson et al. 2000; Robertson et al. 2000).

\section{Subjects and methods}

\section{Subjects}

Ten healthy subjects (six female, four male), median age 30 (range 21-55) years and median BMI 24 (range 20-26) kg/ $\mathrm{m}^{2}$, were studied on three occasions. The subjects satisfied the following inclusion criteria: no previous history of hyperlipidaemia, diabetes or any other endocrine or liver diseases; level of aerobic exercise <three 30 min sessions per week; alcohol intake $<30$ units/week; not trying to lose weight or taking dietary fatty acid supplements. The subjects were recruited following screening for blood lipid and glucose levels which were all within normal limits (mmol/l): (TAG 0.9 (SEM 0.2), total cholesterol 5.0 (SEM 0.4), glucose 5.0 (SEM 0.1). All subjects had normal haemoglobin values.

The present study was approved by the University of Reading and Central Oxford Research Ethics Committees and all subjects gave informed consent at the beginning of the study.

\section{Study-day procedure}

Test meal composition. Subjects were given on each postprandial day at approximately 08.30 hours a high-fat breakfast consisting of a milkshake containing $55 \mathrm{~g}$ corn oil, a bowl of Cornflakes and a banana $(56 \mathrm{~g}$ fat, $73 \mathrm{~g}$ carbohydrate and $13 \mathrm{~g}$ protein). Retinyl palmitate (aqueous form; $2 \mathrm{ml}$, equivalent to $112 \mathrm{mg}$ of retinyl palmitate; Roche, Welwyn Garden City, Herts., UK) was added to the milkshake. At lunch (300 min; 13.30 hours) subjects consumed either $350 \mathrm{ml}$ mineral water (control) or chewed and expectorated a low-fat (LFS; $6 \mathrm{~g}$ fat, $52 \mathrm{~g}$ carbohydrate and $24 \mathrm{~g}$ protein) or moderate-fat (MFS; $38 \mathrm{~g}$ fat, $53 \mathrm{~g}$ carbohydrate and $26 \mathrm{~g}$ protein) meal consisting of a cheese and tomato pizza, a milk drink and mineral water. The nutrient composition of foods was determined from manufacturers' information and from food tables (Holland et al. 1991).

Postprandial study day. On the day before each study day, subjects were asked to avoid strenuous exercise and alcohol, and to consume a low-fat evening meal $(<10 \mathrm{~g}$ fat) before 20.00 hours. Female subjects had their postprandial days standardised to the second half of their menstrual cycle (luteal phase). Subjects attended an investigation unit at either the University of Reading or Radcliffe Infirmary, Oxford following a $12 \mathrm{~h}$ overnight fast on three separate occasions, separated by at least 4 weeks. An indwelling cannula was inserted into the antecubital vein of the forearm and two fasting blood samples were taken before giving the standard breakfast meal, which was consumed within $20 \mathrm{~min}$. Blood samples were taken at hourly intervals until $300 \mathrm{~min}$ after the breakfast test meal when the subjects were randomly allocated to consume water (control), or to chew and expectorate (modified sham feeding) a low-, or moderate-fat meal. Blood samples were collected 10, 20,30, 60, 90, 120 and 180 min following the control and modified sham feeds for the analysis of TAG in both plasma and TAG-rich lipoprotein (TRL) fraction, and of TRL-RE. Additional blood samples were taken at 2 and 5 min following the meals for the analysis of PP and CCK. Between meals, subjects did not consume any other food and decaffeinated sugar-free drinks were taken at regular intervals. The test meals were all well tolerated by the subjects without any unpleasant side effects.

Modified sham feeding protocol. The low- and moderate-fat meals used for modified sham feeding were prepared, at each centre, in a room separate from the clinical investigation unit. At lunch time (300 min following the first meal), the subjects were presented with the test meal and were instructed to chew the food until the point at which they would normally swallow and then to expectorate the food into a plastic container. The subjects rinsed their mouths with the milk drink $(200 \mathrm{ml})$ and mineral water $(150 \mathrm{ml})$ and were continually instructed not to swallow any food or drink by an investigator. Subjects repeated this procedure until the meal had been completely modified sham fed. This procedure took less than $20 \mathrm{~min}$. Weights of each meal were measured before and after modified sham feeding.

\section{Blood collection and analytical methods}

Blood samples were collected into heparinised tubes (L.I.P., Shipley, West Yorkshire, UK) or heparinised syringes (Monovette ${ }^{\mathrm{TM}}$; Sarstedt, Leicester, Leics., UK) for the analysis of plasma TAG, TRL-TAG and TRL-RE and spun at $1700 \mathrm{~g}$ for $15 \mathrm{~min}$. Samples for plasma TAG analysis were stored at $-20^{\circ} \mathrm{C}$ until analysed. Plasma for TRL separation was stored overnight at $4^{\circ} \mathrm{C}$ in sterile glass bottles containing no anticoagulant. The TRL fraction (density $<1.006 \mathrm{~kg} / \mathrm{l}$ ) was prepared by following the 
procedure of Grundy \& Mok (1976) with a few modifications. Plasma (3 ml) was overlayered with $3 \mathrm{ml}$ saline $(9 \mathrm{~g}$ $\mathrm{NaCl} / \mathrm{l}$; density $1.006 \mathrm{~kg} / \mathrm{l})$ and ultracentrifuged in $13.4 \mathrm{ml}$ polycarbonate tubes (Beckman Instruments (UK) Ltd, High Wycombe, Bucks., UK) at $4.82 \times 10^{6} \boldsymbol{g}_{\text {max }}(50000 \mathrm{rpm}$ for $24 \mathrm{~min}$ ) in a $70.1 \mathrm{Ti}$ rotor (Beckman Instruments (UK) Ltd). TRL (creamy layer floating on the surface, $1.0 \mathrm{ml}$ ) was carefully isolated, divided into portions and stored at $-20^{\circ} \mathrm{C}$ for future analyses. Samples for the analysis of RE were covered with $\mathrm{Al}$ foil to protect from degradation by light.

Serum for PP analysis was divided into aliquots and stored at $-80^{\circ} \mathrm{C}$ until analysis. Blood samples for CCK were collected into $\mathrm{K}$ EDTA-coated tubes containing $200 \mathrm{KIU}$ aprotinin/ml blood (Trasylol ${ }^{\mathrm{TM}}$; Bayer plc, Newbury, Berks., UK), centrifuged at $1700 \mathrm{~g}$ for $15 \mathrm{~min}$ and plasma stored at $-20^{\circ} \mathrm{C}$ until analysis. Blood samples for the analysis of PP and CCK were collected between 300 and 480 min only.

Measurement of triacylglycerol, pancreatic polypeptide and cholecystokinin levels. TAG in both the plasma and the TRL fraction was analysed using an IL Monarch centrifugal analyser (Instrumentation Laboratory, Warrington, Ches., UK) using an enzyme-based colorimetric kit supplied by Instrumentation Laboratory. All samples for each subject were analysed within a single batch and the intra-assay $\mathrm{CV}$ for TAG was $1.7 \%$.

Serum PP and plasma CCK were analysed using commercially available radioimmunoassays (Eurodiagnostica, Boldon, Tyne and Wear, UK), with ethanol extraction of CCK before analysis. The intra- and inter-assay $\mathrm{CV}$ for both radioimmunoassays were less than $10 \%$.

Measurement of retinyl esters in the triacylglycerol-rich lipoprotein fraction. Normal phase HPLC was used to measure total RE in the TRL fraction (Ruotolo et al. 1992). The intra-assay CV was $1.9 \%$ at $5 \mu \mathrm{g} / \mathrm{ml}$.

Measurement of the fat content of control and modified sham-fed expectorants. Two identical test meals were prepared for each modified sham fed meal; one was presented to the subject and the second was kept as a control, for comparison to determine if any fat had been eaten inadvertently during modified sham feeding. After modified sham feeding of the low- and moderate-fat meals, the duplicate meals and the expectorants obtained after modified sham feeding were homogenised and then freezedried for a period of $24 \mathrm{~h}$. The samples were then ground using a pestle and mortar and stored in a dessicator until analysed. The fat content of the samples was analysed using the Soxflo method described by Brown \& MuellerHarvey (1999), with previous acid-hydrolysis of the food samples.

\section{Statistical analysis}

Data were analysed using the Statistical Analysis Systems Statistical Software package (SPSS Inc., Chicago, IL, USA). The postprandial data were presented in summary form, i.e. area under the curve and incremental area under the curve (IAUC), and area under the curve values were calculated using the trapezoidal rule (Matthews et al. 1990). In tables data are presented as mean values with the standard errors of the means. The postprandial responses following the first and second meal were analysed using repeated measures ANOVA. Data were checked for normality, and transformed where necessary before statistical analysis was performed. Values of $P<0.05$ were taken as significant

\section{Results \\ Postprandial responses following the first meal (breakfast; 0-300 min)}

The fasting concentrations of plasma and TRL-TAG were not significantly different among postprandial days and are shown in Table 1. Fasting TRL-RE concentrations were below the limit of detection of the HPLC method.

There were no significant differences in the area under the curve or IAUC for the plasma TAG, TRL-TAG or TRLRE responses between 0 and 300 min postprandially (data not shown). Repeated measures ANOVA did not demonstrate any significant meal effects or meal $\times$ time interactions for the postprandial responses between 0 and $300 \mathrm{~min}$ (first and second meal).

The 300 min plasma TAG, TRL-TAG, TRL-RE, PP or CCK concentrations before the control, LFS or MFS protocols were not significantly different. As expected, plasma TAG $(P<0.01)$, TRL-TAG $(P<0.01)$ and TRLRE $(P<0.008)$ concentrations were significantly higher at 300 min compared with fasting concentrations (0 min; Table 1).

\section{Postprandial responses following the second meal (300- $480 \mathrm{~min}$ )}

Repeated measures ANOVA did not demonstrate any significant meal effects or meal $\times$ time interactions for any of the variables measured between 300 and 480 min after receiving water or modified sham feeding. There were also no significant differences in the area under the curve or IAUC for the variables measured between the postprandial responses of the modified sham feeds (LFS and MFS) and that of the control. In the case of plasma and TRL-TAG and TRL-RE, the IAUC for the modified sham feeds demonstrated a tendency to be lower compared with that for the control, but this difference did not reach significance (Table 2). The incremental plasma TAG response from 300 to $480 \mathrm{~min}$ is shown in Fig. 1. Similarly, the IAUC values for CCK were not significantly different, although there was a tendency for higher IAUC on modified sham feeding compared with the control (Table 2). The PP response following both the LFS and MFS showed a superimposable response, with a typical early peak in PP concentrations after the onset of modified sham feeding and returning to $300 \mathrm{~min}$ levels at the end of the sampling period (390 min). The control, on the other hand, showed very little increase in PP levels over the 90 min sampling period (Fig. 2).

\section{Measurement of fat content of modified sham fed expectorants}

The amount of fat recovered from the duplicate meals and 
Table 1. Fasting ( $0 \mathrm{~min}$ ) and postprandial concentrations of plasma and triacylglycerol-rich lipoprotein (TRL)triacylglycerol (TAG), TRL-retinyl ester (RE), pancreatic polypeptide (PP) and cholecystokinin (CCK) 300 min after consumption of the standard breakfast meal $\dagger$

(Mean values with the standard errors of the means for ten subjects)

\begin{tabular}{|c|c|c|c|c|c|}
\hline & \multirow[b]{2}{*}{ Test meal } & \multicolumn{2}{|c|}{ Fasting (0 min) } & \multicolumn{2}{|c|}{ Postprandial (300 min) } \\
\hline & & Mean & SEM & Mean & SEM \\
\hline \multirow[t]{3}{*}{ Plasma TAG $(\mathrm{mmol} / \mathrm{l})$} & Control & 0.89 & 0.16 & $1 \cdot 32^{\star \star}$ & 0.22 \\
\hline & LFS & 0.89 & 0.16 & $1.51^{\star \star}$ & 0.26 \\
\hline & MFS & 0.95 & 0.18 & $1.68^{\star \star}$ & 0.36 \\
\hline \multirow[t]{3}{*}{ TRL-TAG (mmol/l) } & Control & 0.16 & 0.04 & $0.39^{\star \star}$ & 0.08 \\
\hline & LFS & 0.17 & 0.03 & $0.56^{\star \star}$ & 0.14 \\
\hline & MFS & 0.17 & 0.04 & $0.68^{\star \star}$ & 0.17 \\
\hline \multirow{3}{*}{ TRL-RE $(\mu \mathrm{g} / \mathrm{ml})$} & Control & $0 \ddagger$ & & $1.54^{\star \star *}$ & 0.59 \\
\hline & LFS & $0 \ddagger$ & & $2 \cdot 26^{\star \star *}$ & 0.94 \\
\hline & MFS & $0 \ddagger$ & & $1.71^{\star \star \star}$ & 0.58 \\
\hline \multirow{3}{*}{$\mathrm{PP}(\mathrm{pmol} / \mathrm{l})$} & Control & - & & $54 \cdot 6$ & $17 \cdot 7$ \\
\hline & LFS & - & & 53.5 & $15 \cdot 4$ \\
\hline & MFS & - & & 55.5 & 14.5 \\
\hline \multirow[t]{3}{*}{ CCK (pmol/l) } & Control & - & & 4.42 & $1 \cdot 26$ \\
\hline & LFS & - & & 3.21 & 0.63 \\
\hline & MFS & - & & $3 \cdot 24$ & 0.42 \\
\hline
\end{tabular}

LFS, low-fat modified sham fed meal; MFS, moderate-fat modified sham fed meal.

Mean values were significantly different from those fasting concentrations: ${ }^{\star \star} P<0.01,{ }^{\star \star \star} P<0.008$

† For details of procedures, see p. 150.

$\ddagger$ Below the limit of detection of the HPLC method.

from the expectorants collected after modified sham feeding are shown in Table 3. The amount of fat recovered in the expectorant following the LFS was significantly lower than the amount of fat recovered from the duplicate LFS meal $(P<0.05)$, but only by $0.7 \mathrm{~g}$. In the case of the MFS there was no significant difference.

\section{Discussion}

The present study was designed to determine whether cephalic stimulation, generated from eating a meal, could provide the stimulus for the rapid entry into the circulation of TAG eaten with a meal $5 \mathrm{~h}$ previously. Cephalic stimulation is a process whereby the sight, smell, thought and taste of food causes the brain to prepare for the digestion and absorption of the food via activation of the parasympathetic nervous system to release, for example, saliva and gut hormones (Mattes, 1997). In order to achieve a significant cephalic phase response in human subjects modified sham feeding is performed, where food is taken into the mouth, chewed and then expectorated without swallowing. The test meals used in the present study were chosen so that the subjects were unaware of the fat contents. In order to determine whether any of the subjects had inadvertently swallowed any of the meals the expectorant was collected, weighed and analysed. Since plasma and TRL-TAG levels following the second meal were one of the main outcomes of the present study, the total fat content of the expectorant was determined to calculate possible fat ingested during modified sham feeding. In addition, the cephalic phase stimulated hormone PP and gut hormone CCK were measured in the samples collected after water (control) and modified sham feeding.

The results of the present study show that the cephalic stimulation generated from modified sham feeding the lowand moderate-fat meals did not cause an early peak in plasma or TRL-TAG, a response we have previously demonstrated following the ingestion of both fat-free and fat-containing meals (Peel et al. 1993; Fielding et al. 1996; Evans et al. 1998) but not following water (Evans et al. 1998). These findings contrast with those observed by Mattes (1996) who showed an augmented postprandial

Table 2. Incremental area under the curve for the 300-480 min postprandial responses for plasma and triacylglycerol-rich lipoprotein (TRL)-triacylglycerol (TAG), TRL-retinyl ester (RE), pancreatic polypeptide (PP) and cholecystokinin (CCK) following the control and modified sham fed meals ${ }^{*}$

(Mean values with the standard errors of the means for ten subjects)

\begin{tabular}{|c|c|c|c|c|c|c|}
\hline \multirow[t]{2}{*}{ Test meal } & \multicolumn{2}{|c|}{ Control } & \multicolumn{2}{|c|}{ LFS } & \multicolumn{2}{|c|}{ MFS } \\
\hline & Mean & SEM & Mean & SEM & Mean & SEM \\
\hline Plasma TAG (mmol// per $180 \mathrm{~min})$ & $-40 \cdot 6$ & 11.6 & $-65 \cdot 1$ & $17 \cdot 8$ & $-65 \cdot 7$ & $18 \cdot 1$ \\
\hline TRL-TAG (mmol// per 180 min) & -18.4 & 7.7 & $-31 \cdot 0$ & $16 \cdot 1$ & $-46 \cdot 8$ & $16 \cdot 2$ \\
\hline TRL-RE ( $\mu \mathrm{g} / \mathrm{ml}$ per $180 \mathrm{~min})$ & $-98 \cdot 8$ & $38 \cdot 8$ & $-192 \cdot 4$ & $60 \cdot 1$ & $-104 \cdot 0$ & $42 \cdot 4$ \\
\hline $\mathrm{PP}(\mathrm{pmol} / \mathrm{l}$ per $90 \mathrm{~min})$ & $-60 \cdot 7$ & $492 \cdot 7$ & $1893 \cdot 6$ & $851 \cdot 7$ & $1372 \cdot 7$ & $1397 \cdot 5$ \\
\hline $\mathrm{CCK}(\mathrm{pmol} / \mathrm{l}$ per $90 \mathrm{~min})$ & $-59 \cdot 9$ & $100 \cdot 7$ & -0.31 & $54 \cdot 8$ & $55 \cdot 1$ & $62 \cdot 2$ \\
\hline
\end{tabular}

LFS, low-fat modified sham fed meal; MFS, moderate-fat modified sham fed meal

* For details of test meals and procedures, see p. 150. 


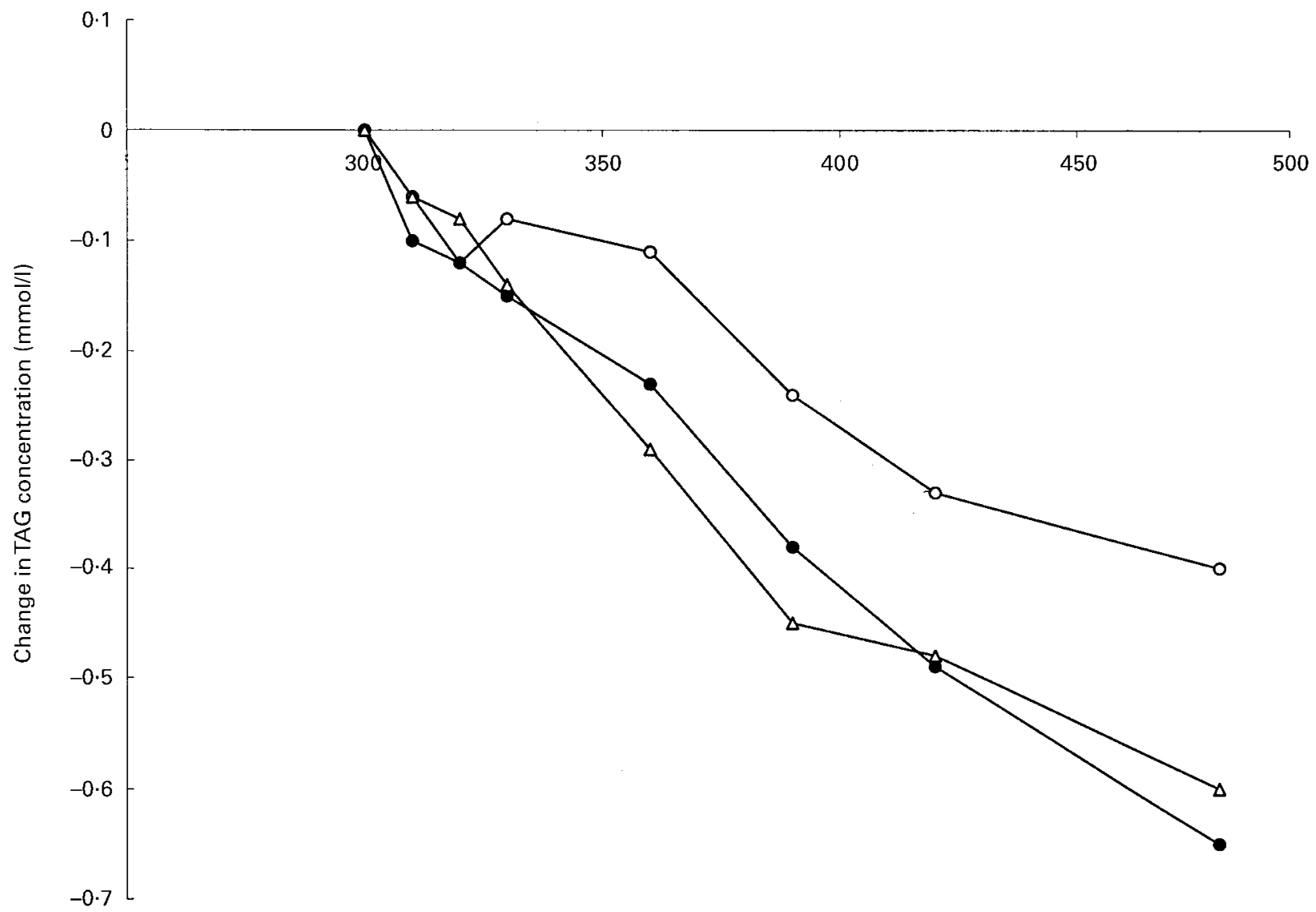

Time after breakfast meal (min)

Fig. 1. Incremental plasma triacylglycerol (TAG) concentrations $(\mathrm{mmol} / \mathrm{l})$ following the control meal $(O)$ and modified sham feeding of the low-fat $(\bullet)$ and moderate-fat $(\triangle)$ meals. Values are mean changes from the TAG concentration at 300 min after the standard breakfast meal for ten subjects. The standard errors are not shown in order to improve clarity of response. For details of test meals and procedures, see p. 150.

TAG response after modified sham feeding a moderate-fat meal. However, the major effect of modified sham feeding observed by Mattes (1996) was on the late postprandial TAG response, suggesting modification of either clearance mechanisms or secretion of VLDL particles from the liver. The present study was designed specifically to investigate potential effects on the release of pre-formed chylomicrons from the enterocyte, so that our negative findings, although suggesting a lack of effect of modified sham feeding at this site, do not exclude potential effects on later stages of chylomicron metabolism. The different study designs used by Mattes (1996) and ourselves may also provide an

Table 3. Total fat $(\mathrm{g})$ recovered from the duplicate low- and moderate-fat meals and the modified sham fed expectorants $\dagger$

(Mean values with the standard errors of the means for ten subjects)

\begin{tabular}{|c|c|c|c|c|c|c|}
\hline \multirow[b]{2}{*}{ Test meal } & \multicolumn{2}{|c|}{ Duplicate meal } & \multicolumn{2}{|c|}{ Expectorant } & \multicolumn{2}{|c|}{ Unrecovered fat } \\
\hline & Mean & SEM & Mean & $\overline{\text { SEM }}$ & Mean & SEM \\
\hline Low-fat & $6 \cdot 2$ & 0.3 & $5 \cdot 5^{*}$ & 0.4 & 0.7 & 0.3 \\
\hline Moderate-fat & $35 \cdot 4$ & 0.5 & $33 \cdot 0$ & 1.5 & $2 \cdot 4$ & 1.4 \\
\hline
\end{tabular}

Mean value was significantly lower than that of the control meal: ${ }^{*} P<0.05$. † For details of the test meals and procedures, see p. 150. explanation for the differences observed. In the study of Mattes (1996), fifty $1 \mathrm{~g}$ safflower oil capsules were ingested before modified sham feeding cream cheese on crackers at regular intervals for $2 \mathrm{~h}$. In the present study, modified sham feeding was carried out $5 \mathrm{~h}$ after a mixed meal (56 g fat) for a duration of less than $20 \mathrm{~min}$. In the study of Mattes (1996), the weight of the expectorant following modified sham feeding provided a crude measure of the success of the modified sham feeding protocols. Measurement of hormonal markers such as PP would have helped to determine whether there had been any swallowing of the test meals, since the contribution of saliva produced during modified sham feeding to the weight of the expectorant may have underestimated any inadvertent ingestion of fat.

The vitamin A loading method was used to label chylomicrons with RE, providing a more specific picture than TRL-TAG of chylomicron-specific postprandial responses after modified sham feeding. In concordance with the TRL-TAG data, modified sham feeding did not cause a rapid release of TRL-RE into the circulation, and this result contrasts with the very early findings of Mendeloff (1954). As before, differences in study design make it difficult to compare these very early findings with 


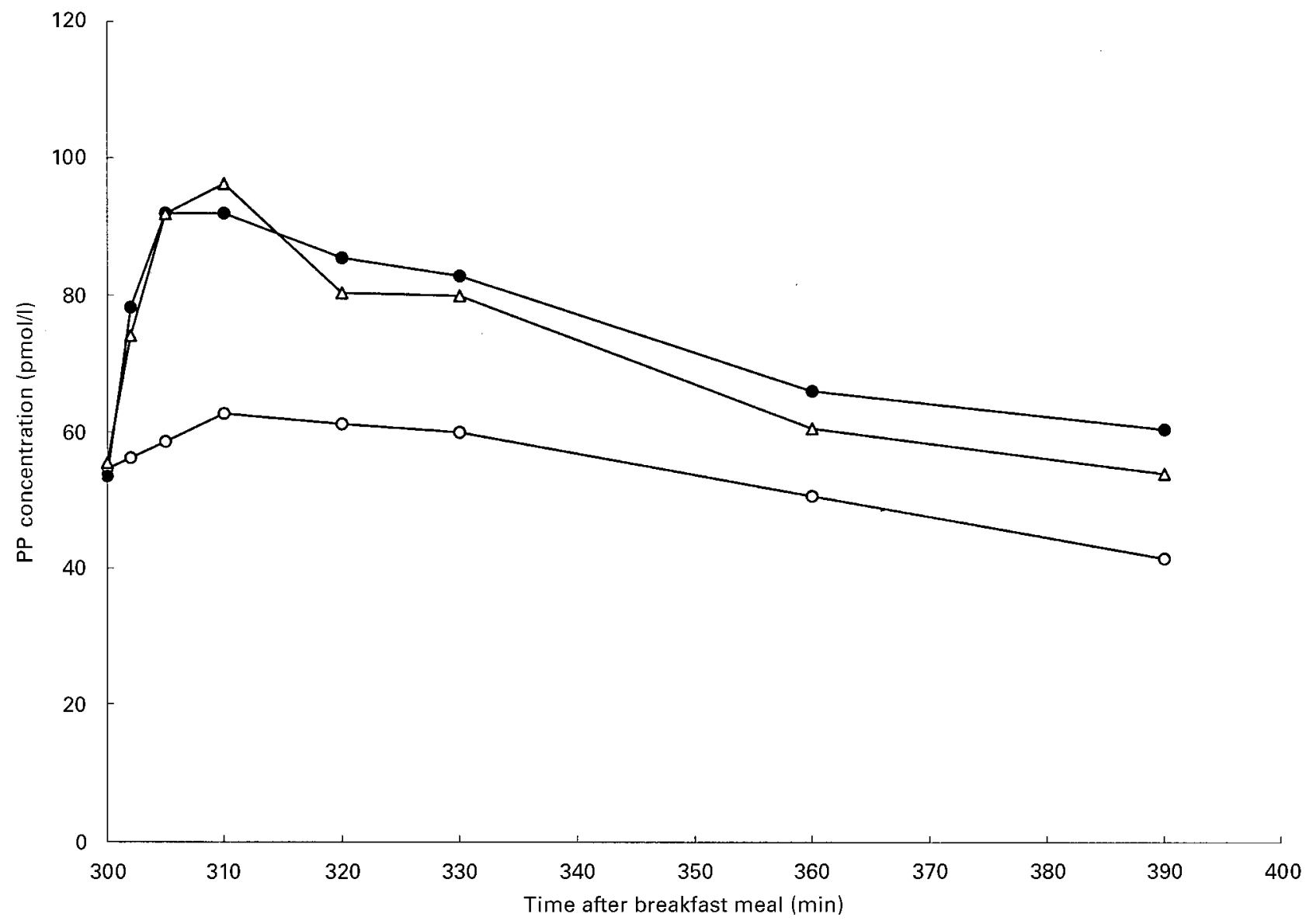

Fig. 2. Pancreatic polypeptide (PP) concentrations (pmol/l) following the control meal $(O)$ and modified sham feeding of the low-fat $(\bullet)$ and moderate-fat $(\triangle)$ test meals at $\mathbf{3 0 0} \mathrm{min}$ after the standard breakfast meal. Values are means for ten subjects; the standard errors are not shown in order to improve the clarity of response. For details of test meals and procedures, see p. 150.

those presented here. In the Mendeloff (1954) study, a rapid entry of vitamin A was observed on modified sham feeding an attractive meal $2 \mathrm{~h}$ following the ingestion of retinyl palmitate in corn oil. However, we did not see any rise in RE concentrations from modified sham feeding $5 \mathrm{~h}$ after the ingestion of a mixed meal containing retinyl palmitate. Mendeloff (1954) stated that the lacteals of animals remain engorged with fat for hours after fed fat has disappeared from the lumen, and that cephalic stimulation somehow activated the lacteals to release their contents. The act of modified sham feeding $2 \mathrm{~h}$ after the retinyl palmitate dose, in contrast to $5 \mathrm{~h}$, may have caused changes in the gastrointestinal handling of the retinyl palmitate and corn oil and caused it to be released rapidly into the circulation. As in the study of Mattes (1996), hormonal markers were not used nor were expectorants analysed to determine whether swallowing of the modified sham fed meals had occurred.

The secretion of PP is under cholinergic control, and the ingestion of food causes a distinct biphasic secretion. The first phase of secretion is due to vagal stimulation (cephalic stimulation) and the second phase corresponds with the presence of food in the gut (Liverse et al. 1993). The lack of the biphasic PP secretion following both the LFS and
MFS suggests that modified sham feeding was carried out successfully. It is also interesting to note that the PP responses following both the modified sham fed meals were very similar despite differences in the fat content of the two meals. Evidence from an earlier study has demonstrated that the composition of the meals used for modified sham feeding was important, with protein and fat increasing the stimulation of PP compared with carbohydrate (Witteman et al. 1994). CCK was used in the present study as a marker for the accidental ingestion of fat during modified sham feeding, as its secretion has been shown to be stimulated by the entry of as little as $2 \mathrm{~g}$ fat into the duodenum (Glasbrenner et al. 1994). However, there is disagreement in the literature as to whether CCK can be released by cephalic stimulation alone. A study by Wisén et al. (1992) in lean and obese subjects showed an unusually early rise in CCK levels on modified sham feeding in the lean subjects compared with the obese subjects. Although the authors proposed that these data supported the possibility of a cephalic phase of CCK secretion, at least in lean subjects, there has been very little other evidence in the literature to support this finding. A recent paper by Raybould et al. (1998) has provided clear evidence for the essential role of chylomicron formation, 
especially the presence of lipid in the intestine, as a signal for the release of $\mathrm{CCK}$ from $\mathrm{CCK}$ endocrine cells. However, further work is required to determine the complete mechanism involved in the release of CCK.

The fat contents of the expectorants collected during modified sham feeding were compared with those of the duplicate meals to determine whether our subjects had accidentally consumed any fat. Many of the studies examining the effects of modified sham feeding on lipid and hormonal responses have used the weight of the expectorant as a measure of the success of the modified sham feeding protocol. However, cephalic stimulation causes saliva release, which would contribute to the weight of the expectorant, thereby masking any loss of food caused by inadvertent ingestion. In the present study the modified sham fed expectorants were collected, weighed and analysed to determine their fat content. The amounts of fat recovered in the expectorants after modified sham feeding both the low- and moderate-fat meals were lower than those of the duplicate meals. However, the maximum losses estimated to have occurred through swallowing would have been 0.7 and $2.4 \mathrm{~g}$ respectively for the low- and moderate-fat meals. These findings, together with the failure to observe a significant elevation in CCK in response to modified sham feeding, support our conclusion that successful modified sham feeding was performed with no significant ingestion of any macronutrients.

In conclusion, cephalic stimulation produced during modified sham feeding low- and moderate-fat meals $5 \mathrm{~h}$ after a previous meal did not cause a rapid entry of preformed TRLs into the circulation. These findings were surprising in view of our previous observations following the ingestion of a meal, irrespective of its fat content (Peel et al. 1993; Fielding et al. 1996; Evans et al. 1998). These data suggest that the stimuli needed to cause the release of stored TAG from a previous meal may require complete ingestion of the second meal rather than the cephalic stimulation associated with eating the meal. A more significant cephalic stimulation is produced on swallowing food compared with tasting and chewing food (Mattes, 1997), indicating that the presence of food in the gut may be one of the necessary stimuli to provoke the release of stored TAG. The events which occur following the ingestion of a fat-containing meal represent the interaction of a number of factors. These factors include intestinal digestion, metabolic processing within the enterocyte, secretion of the nascent chylomicrons and their movement within the lymphatics, and finally their release into the circulation. The mechanism whereby the fat ingested in one meal appears in chylomicrons released within $1 \mathrm{~h}$ of eating a second meal is completely unknown. It has been hypothesised that a proportion of recently ingested fat is retained within the gut lumen, enterocyte or lymphatics. The rapid appearance of chylomicron TAG in the circulation after the second meal would suggest that the fat is present in pre-formed chylomicrons and not as digested fat in the intestine. If the chylomicrons were stored in the enterocyte or the lymphatics, the increase in lymph volume and flow associated with eating and drinking a meal (Mendeloff, 1954) could be responsible for the rapid release of TRLs from the gut. However, further work is required in this area to determine the location of the stored TAG from a previous meal and whether the second meal effect occurs if a meal is eaten later than $5 \mathrm{~h}$ after the first meal.

\section{Acknowledgements}

We would like to thank Mr Ron Brown from the Faculty Analytical Laboratory, University of Reading for his help with the Soxflo analysis and Lesley Deane, Angela Newbury and Jan Luff for their help with the study. The study was supported by a grant from the Biotechnology and Biological Sciences Research Council (BBSRC) UK.

\section{References}

Brown RH \& Mueller-Harvey I (1999) Evaluation of the novel soxflo technique for rapid extraction of crude fat in foods and animal feeds. Journal of the Association of Official Analytical Chemists International 82, 1369-1374.

Evans K, Kuusela PJ, Cruz ML, Wilhelmova I, Fielding BA \& Frayn KN (1998) Rapid chylomicron appearance following sequential meals: effects of second meal composition. British Journal of Nutrition 79, 425-429.

Fielding BA, Callow J, Owen RM, Samra JS, Matthews DR \& Frayn KN (1996) Postprandial lipaemia: the origin of an early peak studied by specific dietary fatty acid intake during sequential meals. American Journal of Clinical Nutrition 63, 36-41.

Glasbrenner B, Dominguez-Munoz JE, Nelson DK, Pieramico O, Holzworth C, Riepl RL \& Malfertheiner P (1994) Postprandial release of cholecystokinin and pancreatic polypeptide in health and gallstone disease: Relationships with gallbladder contraction. American Journal of Gastroenterology 89, 404-410.

Grundy SM \& Mok HYI (1976) Chylomicron clearance in normal and hyperlipidemic man. Metabolism 25, 1225-1291.

Holland BA, Welch AA, Unwin ID, Buss DH, Paul AA \& Southgate DAT (1991) McCance and Widdowson's The Composition of Foods, 5th ed. Cambridge: Royal Society of Chemistry.

Jackson KG, Robertson MD, Deane LO, Fielding BA, Frayn KN \& Williams CM (2000) The effect of modified sham feeding meals of varying fat content on postprandial triacylglycerol, insulin and glucose responses. Proceedings of the Nutrition Society 59, 14A.

Liverse RJ, Masclee AAM, Jansen JBMJ \& Lamers CBHW (1993) Plasma cholecystokinin and pancreatic polypeptide secretion in response to bombesin, meal ingestion and modified sham feeding in lean and obese persons. International Journal of Obesity 18, 123-127.

Mattes RD (1996) Oral fat exposure alters postprandial lipid metabolism in humans. American Journal of Clinical Nutrition 63, 911-917.

Mattes RD (1997) Physiologic responses to sensory stimulation by food: Nutritional implications. Journal of the American Dietetic Association 97, 406-413.

Matthews JNS, Altman DG, Campbell MJ \& Royston P (1990) Analysis of serial measurements in medical research. British Medical Journal 300, 230-235.

Mendeloff AI (1954) The effects of eating and of sham feeding upon the absorption of vitamin A palmitate in man. Journal of Clinical Investigation 33, 1015-1021.

Patsch JR, Miesenbock G, Hopferwieser T, Mühlberger V, Knapp E, Dunn JK, Gotto AM Jr \& Patsch W (1992) Relation of triglyceride metabolism and coronary heart disease. Studies 
in the postprandial state. Arteriosclerosis and Thrombosis 12 1336-1345.

Peel AS, Zampelas A, Williams CM \& Gould BJ (1993) A novel antiserum specific to apolipoprotein B-48: application in the investigation of postprandial lipidaemia in humans. Clinical Science 85, 521-524.

Raybould HE, Meyer JH, Tabrizi Y, Liddle RA \& Tso P (1998) Inhibition of gastric emptying in response to intestinal lipid is dependent on chylomicron formation. American Journal of Physiology 274, R1834-R1838.

Robertson MD, Jackson KG, Williams CM, Fielding BA \& Frayn KN (2000) Modified sham feeding of a modest-fat meal suppresses plasma non-esterified fatty acids. Proceedings of the Nutrition Society 59, 123A.

Ruotolo G, Zhang H, Bentsianov V \& Le N-A (1992) Protocol for the study of the metabolism of retinyl esters in plasma lipoproteins during postprandial lipaemia. Journal of Lipid Research 33, 1541-1549.

Wisén O, Björvell $\mathrm{H}$, Cantor P, Johansson C \& Theodorsson E (1992) Plasma concentrations of regulatory peptides in obesity following modified sham feeding (MSF) and a liquid test meal. Regulatory Peptides 39, 43-54.

Witteman BJM, Edwards-Teunissen K, Hopman WPM, Jebbink MCW, Masclee AAM, Lamers CBHW \& Jansen JBMJ (1994) Nutrient-specific effects of modified sham feeding on pancreatic polypeptide release. European Journal of Clinical Nutrition 48, 556-560.

Zilversmit DB (1995) Atherogenic nature of triglycerides, postprandial lipidemia and triglyceride-rich remnant lipoproteins. Clinical Chemistry 41, 153-158. 